\title{
POLARIZAÇÃO DE GRUPOS E VULNERAÇÃO DAS MINORIAS: OS EFEITOS DO RACISMO NOS ALTOS ÍNDICES DA VIOLÊNCIA CONTRA NEGROS NO BRASIL
}

\author{
Izabella Viana de Medeiros ${ }^{1}$ \\ Paulo Márcio Rei Santos ${ }^{2}$
}

Resumo: O presente artigo propõe-se a analisar a polarização de grupos no Brasil, com a aparente colisão entre grupos autodenominados conservadores ou de direita, em oposição a grupos de esquerda ou ditos progressistas. E como está polarização gera um incremento na violência contra grupos minoritários, em especial os negros, promovendo o racismo e os altos índices de violência contra os negros no Brasil. Assim se tem como problema de pesquisa a indagação acerca da relação entre a polarização e a vulneração de grupos minoritários, e qual o potencial incremento do racismo e nos índices de violência contra a população negra.

Palavras-chave: Racismo; Polarização; Minorias; Vulneração; Violência

\section{POLARIZATION OF GROUPS AND VULNERATION OF MINORITIES: THE EFFECTS OF RACISM ON THE HIGH RATES OF VIOLENCE AGAINST BLACKS IN BRAZI}

\begin{abstract}
This article intends to analyze the polarization in Brazil with the apparent collision between self-styled conservative or right-wing groups, as opposed to left-wing groups or socalled progressives. And how this polarization generates an increase in violence against minority groups, especially blacks, promoting racism and the high rates of violence against blacks in Brazil. Thus, the research problem is the question about the relationship between the polarization of groups and the vulneration of minority groups, and what is the potential increase in racism and in the rates of violence against the black population..
\end{abstract}

Keywords: Racism; Polarization; Minority; Vulneration; Violence

\section{INTRODUÇÃO}

De acordo com os dados do Atlas da Violência 2020, publicado pelo Instituto de Pesquisa Econômica Aplicada (IPEA), entre 2008 e 2018, as taxas de homicídios apresentaram um aumento de 11,5\% para negros, enquanto para os não negros houve uma diminuição de $12,9 \%$. Ainda, constatou-se que $75 \%$ das vítimas de homicídio no país são

\footnotetext{
${ }^{1}$ Advogada do Instituto de Neurociência da Bahia. Bacharel em Direito pela Escola Superior Dom Helder Câmara. Mestre em Direito Privado no PPGD FUMEC. Rua Almirante Barroso, n.248, ap. 101 Bela Vista A, Condomínio Bahia Bela, Rio Vermelho, Salvador, BA, CEP 41.950.350. E-mail: izabellaviana22@gmail.com.

${ }^{2}$ Sócio fundador da PMRS Advocacia e Consultoria. Doutor e Mestre em Direito pela Universidade Federal de Minas Gerais. Professor no Mestrado e na Graduação em Direito da Universidade FUMEC. Rua Paulista, n.801, ap. 502, Fernão Dias, Belo Horizonte, MG, CEP 31910-532. E-mail: paulo.marcio@ fumec.br.
} 
negras (INSTITUTO BRASILEIRO DE GEOGRAFIA E ESTATÍSTICA, 2020).

Destaque também para o Anuário Brasileiro de Segurança Pública de 2019, que divulgouque $74,5 \%$ das pessoas mortas em intervenções policiais são negras (FÓRUM BRASILEIRO DE SEGURANÇA PÚBLICA, 2020).

Dados estatísticos que atestam a vulneração dos negros no Brasil, levanta o questionamento sobre o racismo, ainda tão presente na sociedade brasileira. Trata-se o racismo de sistema de marcas físicas, visíveis, as quais se associa a "essência de um grupo", como se os indivíduos pertencentes àquele grupo possuem os mesmos valores morais, culturais e intelectuais e é através do sangue que essa essência é transmitida (GUIMARÃES, 2009, p. 30). Por anos, os negros foram estigmatizados como violentos, sexualizados e dotados de pouca inteligência. Foram, em suma, animalizados pela sociedade.

A tudo isso, soma-se, ainda, um quadro cada vez mais acentuado de polarização, potencializado pela capilarização das redes sociais e a formação de bolhas on-line, com a aparente colisão entre grupos autodenominados conservadores ou de direita, em oposição a grupos de esquerda ou ditos progressistas.

A polarização de grupos, segundo Cass R. Sunstein, é o fenômeno de radicalização de opiniões que ocorre "[...] quando as pessoas se encontram em grupos detipos que pensam de modo semelhante, [e] ficam particularmente propensas a se mover para os extremos" (SUNSTEIN, 2010, p. 4), homogeneizando discursos, com impactos em diversos setores, inclusive político e jurídico.

Assim, o problema de pesquisa indaga acerca da relação entre a polarização de grupos e a vulneração de grupos minoritários, em especial, os negros, promovendo o racismo, elevando os indicies de violência contra este grupo e malferindo da dignidade da pessoa humana.

Como hipótese, afirma-se que a crescente polarização de grupos fomenta a intolerância e o racismo, ultrapassando a esfera do debate político ou civil, contaminando o ordenamento jurídico. Assim, a polarização contribui para a vulneração de grupos, em especial dos negros, malferindo o princípio da dignidade da pessoa humana.

Justifica-se a pesquisa pela necessidade de entender, ante os dados estatísticos oficiais de violência no Brasil, após 2019, onde os negros figuram como as maiores vítimas, se a polarização de grupos fomenta o racismo e promove a vulneração deste grupo, 
impactando positivamente na violência.

O objetivo geral da pesquisa é investigar a relação entre polarização de grupos, racismo e a vulneração das minorias, em especial, os negros.

São objetivos específicos da pesquisa: (a) analisar o fenômeno da polarização de grupos no Brasil pós-redemocratização, identificando eventuais impactos no ordenamento jurídico em desfavor das minorias; (b) identificar o que são minorias, e como ocorre a sua vulneração; (c) compreender o racismo e identificar o quadro atual de crimes violentos no Brasil, em especial contra negros (d) e por fim, analisar os dados estatísticos oficias que demonstram a vulneração da população negra.

O desenvolvimento da pesquisa estrutura-se em três capítulos. No capítulo dois será apresentado o conceito de polarização de grupos, e como esses se desenvolveram no Brasil pós-redemocratização.

No capítulo três será estudado como a polarização afeta diretamente a política e ordenamento jurídico brasileiro, vulnerando minorias e como ocorre está vulneração.

No capítulo quatro será analisado o racismo e a violência contra negros no Brasil, a definição de racismo, inclusive os conceitos de racismo estrutural e institucional.

Por fim, no capítulo cinco serão apresentados dados estatísticos sobre a desigualdade social por cor ou raça no Brasil, além da taxa de homicídios e crimes violentos no país.

A pesquisa adota, como marcos teóricos convergentes, o conceito de polarização de grupos de Cass R. Sunstein (SUNSTEIN, 2010, p. 4); e, o conceito racialista de Sérgio Alfredo Guimarães (GUIMARÃES, 2009, p. 30).

Quanto aos demais aspectos metodológicos, a pesquisa se insere na perspectiva jurídico-social (GUSTIN; DIAS, NICÁCIO, 2020), adotando como raciocínio predominante o hipotético dedutivo; é realizada em perspectiva interdisciplinar, por meiode pesquisa bibliográfica e documental, com dados de natureza primária e secundária.

\section{POLARIZAÇÃO DE GRUPOS}

Cass R. Sunstein, na obra "A era do Radicalismo", analisa o fenômeno da polarização de grupos. Partindo de análises empíricas, o autor observa que grupos de pessoas que se reúnem para conversar com indivíduos que pensam de modo semelhante 
ficam propensas a se tornarem extremistas. Em geral, acabam em "uma posição mais extrema na mesma direção para qual estavam inclinadas antes do início da discussão". Ao separar os seus membros do restante da sociedade, seja física ou psiquicamente, “cria-se um sentimento de desconfiança em torno dos não membros, tornando estes descreditados, o que facilitará o processo de polarização", enquanto somente os membros mantém diálogo. Segundo Sunstein, essa polarização ocorre no cotidiano e "está presente em praticamente todas as decisões, desde decisões econômicas ao que beber e onde morar" (SUNSTEIN, 2010, p. 4-6).

A esse respeito, Bruno Paiva Bernardes sustenta que em um cenário de polarização de grupos, “[...] a deliberação pode funcionar de forma equivocada, fazendo com que pessoas que pensam de forma assemelhada possam chegar a posições extremadas." (BERNARDES, 2019, p. 28).

O extremismo, gerado pela polarização de grupos, “é uma ameaça à segurança, à paz, ao desenvolvimento econômico e à tomada de decisões sensatas" (SUNSTEIN, 2010, p. 3-4). Torna-se ainda "mais perigoso quando há a presença de uma autoridade, que dizaos membros o que fazer, confere certos papéis sociais", como pode ser observado ao longo dos anos, ao redor do mundo (SUNSTEIN, 2010, p. 3-4).

A ansiedade de status e o estilo paranoico estudados por Richard Hofstadter, no ensaio "The paranoid style in america politics", também explica a polarização que ocorrena atualidade. Esse estilo tem a propensão de emergir quando "o status, a identidade e o sentido de pertencimento de grupos sociais são percebidos como estando sob ameaça", conduzindo a "um estilo de política que é excitável demais, desconfiado, agressivo e pretensioso" (HOFSTADTER, 1996, p. 3-6).

Quando esse estilo ganha força, ocorre uma mudança no debate político; o foco da disputa e da polarização deixou de ser somente econômico e governamental, e passou para questões relacionadas à cultura, aos costumes e comportamento. Propostas concretas, como planos econômicos, são de menor importância; questões de cunho moral, como aborto e educação sexual em escolas, se tornaram o centro da discussão.

E qual é o problema da polarização política? Em “Como as democracias morrem”,são apresentados critérios que se fazem necessários para a sobrevivência da democracia, sendo estes: o respeito às regras democráticas do jogo, o reconhecimento da legitimidadedos adversários, a tolerância e o diálogo (LEVITSKY; ZIBLATT, 2018, p. 32-33). 
O excesso de polarização compromete todos os critérios que mantêm a democracia viva, pois o adversário é visto como inimigo; não há diálogo e transgredir asregras se torna justificável. A polarização afeta a democracia.

\subsection{POLARIZAÇÃO DE GRUPOS NO BRASIL}

A política contemporânea no Brasil está muito associada à dinâmica da polarização de grupos. Esta remete à divisão de uma sociedade em dois polos que não dialogam entre si; fecham-se nas suas convicções e disputam o poder.

Os pesquisadores Pablo Ortellado e Márcio Moretto Ribeiro, em parceria com a Universidade de São Paulo, publicaram uma pesquisa no ano de 2018 que analisou o comportamento dos brasileiros no Facebook, rede social favorita no país. Restou demonstrado que 52\% dos brasileiros consomem notícias advindas dessa rede social. Contabilizou-se aproximadamente 12 milhões de brasileiros interagindo com páginas políticas. Ao traçarem as interações desses usuários, foi desenvolvido um mapa da opinião política brasileira e suas mudanças ao decorrer dos anos (ORTELLADO; RIBEIRO, 2018).

Os usuários brasileiros foram categorizados em seis comunidades, com base nos tipos de página que visitavam: políticos e partidos conservadores; políticos e partidos de esquerda; grupos anticrime; campanhas anticorrupção; movimentos sociais progressistas e direitos humanos e ambientalismo (ORTELLADO; RIBEIRO, 2018).

Essas comunidades se distribuíam entre esquerda e direita. Havia uma clara diferença entre o comportamento on-line desses indivíduos, mas a distância entre os movimentos sociais em 2013 não era tão grande. Alguns pertenciam a mais de um grupo, como brasileiros interessados em movimentos progressistas e que também seinteressaram no movimento anticorrupção. Outros pautavam-se no discurso da anticorrupção, mas também se filiaram ao ambientalismo (ORTELLADO; RIBEIRO, 2018).

No entanto, em junho de 2013, começaram a ocorrer protestos massivos contra o aumento nas tarifas de ônibus e metrô iniciados nas cidades de São Paulo e Rio de Janeiro.A agitação se expandiu, cerca de $12 \%$ da população foi às ruas, englobando locais e demandas diferentes, como a Copa do Mundo e as Olimpíadas que seriam sediadas no 
país e exigiriam financiamento governamental, o que os brasileiros requeriam que fosse revertido aos serviços públicos (ORTELLADO; RIBEIRO, 2018).

No final de 2013, apontou a pesquisa, o comportamento de mídia social das pessoas começou a mudar. Os cidadãos do movimento anticorrupção começaram a focar nas postagens de políticos de direita, ao passo que os cidadãos que se interessavam nos movimentos sociais progressistas no Facebook passaram a focar nas postagens de políticos esquerdistas. Os partidos políticos começaram a colocar estas questões na frente de suas plataformas, distanciando a esquerda e a direita, separando a sociedade politicamente (ORTELLADO; RIBEIRO, 2018).

A polarização observada pela pesquisa endureceu entre os anos de 2014 e 2016. Os usuários que se dividiam em seis comunidades de interesses distintos no Facebook se separaram em dois grupos com poucos interesses comuns: os progressistas e os conservadores (ORTELLADO; RIBEIRO, 2018).

Como observado anteriormente, neste cenário polarizado, o debate político é contaminado, propostas concretas, como planos econômicos, são deixadas de lado e questões de cunho moral, como aborto e educação sexual em escolas, se tornaram o centroda discussão.

\section{O QUE SÃO AS MINORIAS E COMO OCORRE SUA VULNERAÇÃO}

Os grupos dominantes podem utilizar a violência como um meio natural de solução de conflitos, seja nas relações entre classes sociais ou intersubjetivas. A violênciase torna um dos maiores geradores de vulnerabilidade das minorias (CARMO, 2016, p. 205).

Segundo Arendt, movimentos totalitários observados no mundo inteiro, emergiam quando encontravam massas de longa duração que possuíam motivos para odiar todos os partidos, pessoas e minorias, é uma fração da população que só se preocupa com o seu próprio poder, são apolíticos (ARENDT, 1997, p. 362) e desta forma buscam um outsider ${ }^{1}$ para fazer valer suas vontades. No Brasil, pode ser observada a formação de uma massa ultraconservadora, liberal (economicamente), de direita e que reproduz um

\footnotetext{
${ }^{1}$ Segundo o Grande Dicionário Houaiss, "indivíduo que não pertence a um grupo determinado; [...] investidor que não tem acesso às informações de uma empresa; [...] competidor sem probabilidade de ganhar;
} 
azarão; zebra." (OUTSIDER, 2021). 
discurso de ódio contra as minorias e grupos vulneráveis, através das palavras e medidas legislativas professadas pelo líder. Importante ressaltar que as minorias e os grupos vulneráveis originam-se de relações de assimetria social, seja ela econômica, educacionalou cultural (CARMO, 2016, p. 205).

O conceito de minoria ou de grupos minoritários é compreendido e debatido de diversas formas por diferentes pesquisadores e áreas. José Ricardo Carvalheiro, em sua pesquisa sobre representação, definiu o conceito de minoria sob o aspecto do diferente e do numericamente menor, o que os tornaria invisíveis e estereotipados (CARVALHEIRO, 2006, p. 77). Theophilos Rifiotis define como minoria os grupos que poderiam, em circunstâncias específicas, correr o risco de perder a própria identidade por se tornarem vítimas do processo de controle e homogeneização (RIFIOTIS, 2006, p. 8-9). Elida Séguin, parte de uma perspectiva jurídica: os grupos minoritários são aqueles sofrem discriminação e são vítimas de intolerância (SÉGUIN, 2002, p. 12)

Mencione-se, ainda, a teoria que conceitua a palavra minoria como simbolismo ético-político dentro de uma luta contra hegemônica. A definição está atrelada à democracia representativa, em que predomina a vontade da maioria quantitativa, mas, qualitativamente, a democracia é um regime das minorias. É no processo democrático que a minoria pode se fazer ouvir, é a fusão mobilizadora do grupo para ser ouvido, é a recusa do consentimento, é a procura por abertura no círculo fechado das determinações sociais (CARMO, 2016, p. 204-205).

Nos variados conceitos dados aos grupos minoritários ou grupos vulneráveis, existem pontos em comum, como a falta de poder, a dominação a qual são submetidos, a violência sofrida e a marginalização (CARMO, 2016, p. 203-204). Séguin diferencia a concepção de minorias e grupos vulneráveis: as minorias são caracterizadas por não ocuparem uma posição de dominância no país onde vivem; já os grupos vulneráveis também não ocupam a posição de dominância, mas são constituídos por um contingente maior de pessoas (SÉGUIN, 2002, p. 12). Apesar de realizar a diferenciação, Séguin esclarece que tanto os grupos vulneráveis quanto as minorias sofrem discriminação e são vítimas de intolerância, razões pelas quais não se preocupa em trabalhar essas categorias de forma distinta (SÉGUIN, 2002, p. 12).

Wendy Rogers e Angela Ballantyne, em pesquisa sobre populações especiais, vulnerabilidade e proteção, conceituaram uma tipificação básica das fontes de 
vulnerabilidade. A primeira fonte é a vulnerabilidade extrínseca, ocasionada por circunstâncias externas, como falta de poder socioeconômico, pobreza, falta de escolaridade ou carência de recursos; a segunda é a vulnerabilidade intrínseca, ocasionada por características dos próprios indivíduos, como doença mental, deficiência intelectual ou extremos etários. Ressaltam que, geralmente, as pessoas com vulnerabilidade intrínseca também são extrinsecamente vulneráveis e que estas vulnerabilidades podem estar relacionadas a indivíduos ou a populações (ROGERS; BALLANTYNE, 2008, p. 41)

A vulnerabilidade extrínseca causa diversos efeitos. Um deles é a falta de poder, em que são negados, injustamente, direitos sociais e políticos a certos grupos. Cada uma dessas vulnerabilidades requer diferentes mecanismos de proteção para proteger os cidadãos dos danos e da exploração (ROGERS; BALLANTYNE, 2008, p. 41).

A vulnerabilidade dessas minorias advém da pressão de grupos majoritários, do suposto padrão de normalidade, que pressiona a todos que podem ser considerados diferentes. Ela gera uma violência física ou simbólica, que muitas vezes vem na forma de rejeição, preconceito, marginalização e discriminação do diferente (CARMO, 2016, p. 206).

É neste campo que o racismo de estado se desenvolve, por meio do biopoder queé um poder regulamentar, em que as questões de natalidade, mortalidade, pobreza, sobre a vida humana são ligadas a diferenças biológicas, não são somente políticas e sociais, mas científicas. Nesse cenário, o racismo ganha destaque, pois separa a população e cria o conflito, porque ao separar a população em diversos grupos biológicos, um deles pode ser visto como ameaçador, como perigoso e passa a ser perseguido pelos demais.

O racismo de Estado funciona por meio de preconceitos, discriminação, intolerâncias infundadas, que somente servem como uma justificativa para a violência, para a intervenção estatal, medidas segregatórias, de guetização e genocídio, tudo como uma forma de conter o inimigo (GONTIJO; BICALHO, 2019, p. 259). Trata-se de uma forma de manutenção do poder da maioria, pois retira do governo a responsabilidade pelas desigualdades sociais, já que agora não se trata de construções sociais, mas sim biológicas (GONTIJO; BICALHO, 2019, p.263). E a sociedade polarizada deixa de se preocupar com aquele que pensa ideologicamente diferente ou é considerado "biologicamente inferior", pois este se torna inimigo, desta forma a discriminação, racismo e a intolerância ganham força. 


\section{RACISMO E VIOLÊNCIA CONTRA NEGROS NO BRASIL}

O significado do termo "raça" sempre esteve ligado a uma forma de se estabelecer classificações em todas as espécies, sejam elas vegetais ou animais (ALMEIDA, 2019, p. 18). A noção que se tem do que é ser homem atualmente, construída pela filosofia, teve início com o ideário iluminista "o homem como objeto principal”. O sujeito se torna objeto de estudo, suas versões e diferenças são dignas de serem conhecidas. Surgem, destaforma, os aspectos de comparação que, posteriormente, se transformam em critérios de classificação (ALMEIDA, 2019, p. 18-19).

O Iluminismo foi o fundamento para que revoluções fossem iniciadas, deixando de lado conceitos teocráticos e absolutistas. O mundo sofreu um processo de reorganização com a transição de sociedades feudais para capitalistas, em que os sujeitospossuíam direitos universais (ALMEIDA, 2019, p. 19).

As civilizações inglesas, americanas e francesas, iluministas, começaram expedições para lugares do mundo onde não havia o conhecimento sobre os ideais de liberdade, igualdade e civilidade. O processo de levar a civilização para outras localidades resultou em destruição e morte "em nome da razão e da liberdade", processo conhecido como o "colonialismo" (ALMEIDA, 2019, p. 19).

Dessa forma, a classificação dos seres humanos não é só uma preocupação filosófica, mas uma forma de controle por submissão e destruição de populações pelo colonialismo europeu (ALMEIDA, 2019, p. 20).

A crença na diferença entre as raças ganhou tanta força que, de objeto filosófico, passou a ser vista como científico, momento em que surgiu a ideia da diferença por características biológicas ou condições climáticas e ambientais, que seriam as responsáveis pelas diferenças psicológicas, intelectuais e morais entre as raças. "Desse modo, a pele negra e o clima tropical favoreciam o surgimento de comportamentos imorais, lascivos e violentos, além de indicarem pouca inteligência (ALMEIDA, 2019, p.21). Ainda hoje, a noção de raça se fundamenta numa concepção científica. No entanto, existem aqueles que se opõem ao conceito de raça pelas Ciências Sociais, valendo-se dos argumentos de que a Biologia nega a existência de raças humanas; outrosentendem que o termo é impregnado de ideologias opressivas e que seu uso não trará benefícios; ao contrário, só perpetuaria a justificativa naturalista de desigualdade entre osgrupos (GUIMARÃES, 2009, p. 21-22). 
A corrente que sustenta a utilização do termo "raça" pelas Ciências Sociais o faz por entender necessário demonstrar o caráter específico de um subconjunto de práticas ecrenças discriminatórias. Em contrapartida, para aqueles que sofrem ou sofreram os efeitos do racismo, não existiria alternativa senão reconstruir, de modo crítico, os paradigmas dessa ideologia (GUIMARÃES, 2009, p. 22).

Esta pesquisa será baseada na defesa do uso do termo "raça" tal como concebido pelas Ciências Sociais, já que se trata de conceito construído pelo imaginário social, sem respaldo biológico (GUIMARÃES, 2009, p. 22). Buscar-se-á demonstrar os efeitos do racismo e as alternativas para a reconstrução dessa ideologia.

Surgem duas formas distintas, mas complementares, de racismo: o racismo pela característica biológica, em que a identidade racial é atribuída por algum traço físico (corda pele ou textura do cabelo, por exemplo); e o racismo cultural, em que a identidade está associada à origem geográfica, os costumes e a religião (ALMEIDA, 2019, p. 22).

Foi somente após a Segunda Guerra Mundial que a Organização das Nações Unidas para Educação, a Ciência e a Cultura (UNESCO) reuniu geneticistas e cientistas para estudarem as ligações entre "raça" e as "relações raciais", constatando que diferenças fenotípicas, culturais e intelectuais não podiam ser atribuídas a diferenças biológicas, massim a construções sociais e condições ambientais (GUIMARÃES, 2009, p. 23-24).

Antropológica e biologicamente não foi demonstrado que as determinações culturais ou biológicas são capazes de determinar a moral ou a inteligência de alguém, ouseja, não há nada de natural no conceito raça, é um elemento político (ALMEIDA, 2019,p. 22).

Por isso é necessário definir a teoria em que o conceito de "raça" tem vigência. Será adotado nesta pesquisa o termo "racialismo", de Antônio Sérgio Alfredo Guimarães, que utiliza, em parte, do conceito de Kwame Anthony Appiah:

\begin{abstract}
Existem pelo menos três doutrinas distintas que podem ser desenvolvidas para expressar o conteúdo teórico do que chamamos de "racismo". Uma é a visão -que chamarei de racialismo - de que existem características hereditárias, possuídas por membros de nossa espécie, que nos permitem dividi-los em um pequeno conjunto de raças, de modo que todos os membros dessas raças compartilham certos traços. e tendências mútuas que não compartilham com membros de nenhuma outra raça. Esses traços e tendências característicos da raça constituem, na visão do racismo, uma espécie de essência racial; e é parte do conteúdo do racialismo que as características hereditárias essenciais daquiloque o século XIX chamou de Raças do Homem respondem por mais do que as características morfológicas visíveis - cor da pele, tipo de cabelo, traços faciais - com base nas quais fazemos nossas classificações informais. (APPIAH, 1990, p. 5 , tradução nossa). ${ }^{2}$
\end{abstract}

O conceito sociológico criado por Antônio Sérgio altera em dois aspectos o conceito 
de Kwame Anthony Appiah (APPIAH, 1990). Segundo ele, em primeiro lugar, trata-se de sistema de marcas físicas, visíveis, às quais se associa uma "essência", que consiste na ideia de que aquele grupo possui os mesmos valores morais, cultuais e intelectuais. Em segundo, apesar de todo "racialismo" necessitar da ideia de "sangue" como perpetuador dessa "essência", as regras de transmissão podem variar segundo diferentes racialismos (GUIMARÃES, 2009, p. 30).

Ressalta-se a diferenciação derivada da doutrina racialista entre dois tipos de racismo: o extrínseco e o intrínseco. O primeiro traça distinções morais entre membros de diferentes raças, acreditando que a essência racial implica em certas qualidades moralmente relevantes em que se distinguem em certos aspectos, como a honestidade, a coragem ou a inteligência, e é essa diferenciação que autoriza um tratamento desigual. Já o racista intrínseco acredita que cada raça possui um status moral diferente, ligadas à sua essência racial, o que derivaria um interesse moral comum. Dessa forma, para o racista intrínseco, só pelo fato de a pessoa ser da mesma raça haveria razão plausível para se preferir uma pessoa a outra (GUIMARÃES, 2009, p. 34-35).

Para compreender o estudo do racismo no Brasil no campo da pesquisa científica, deve-se compreender a inspiração norte-americana. Isso porque os cientistas tomaram o padrão de relações raciais norte-americanas para compreender a construção social das raças em outras sociedades, inclusive no Brasil (GUIMARÃES, 2009, p. 41).

Os norte-americanos, por utilizarem o sistema de "uma gota de sangue negro fazde alguém um negro", possuem suas raças bem definidas (GUIMARÃES, 2009, p. 45). No Brasil não há uma regra clara de descendência biológica definindo grupos raciais. As classificações se dão a partir da aparência física e da interação entre "status adquiridos e adscritos" (GUIMARÃES, 2009, p. 45).

Dessa forma, a análise científica do racismo, feita sob o modelo americano, acabou por esconder a existência das raças e da discriminação racial no Brasil. Diferentemente do modelo norte-americano, que exibia uma violência elevada, segregacionista, conhecido como modelo "Jim Crow", o modelo brasileiro possui certo verniz de distanciamento social, de diferenciação de possibilidades econômicas. Por isso é que foi um tabu, até recentemente, e os brasileiros se imaginavam numa democracia racial, em razão da visão deturpada do racismo sob o viés norte-americano (GUIMARÃES, 2009, p. 39-42).

No Brasil, historicamente, muito se falava no conceito de "democracia racial", em que, supostamente, pretos e brancos conviviam pacificamente, possuindo os mesmo direitos 
e deveres (NASCIMENTO, 1978, p. 41). No entanto, essa democracia racial era compulsória, pois são os brancos os "porta-vozes oficiais da nação", detentores do poder político, econômico e social, que controlam os meios de disseminação de informações, o sistema educacional, e formulam os conceitos e os valores do país (NASCIMENTO, 1978, p. 45-46).

O "mulato, situado no meio do caminho, entre a casa grande e a senzala", filho do estupro da mulher negra escravizada, tornou-se o símbolo da "democracia racial brasileira". O "processo de mulatização", a mistura das raças, é visto como algo bom, pela prevalência do elemento superior, com o objetivo de clarear e eliminar a população negra do país (NASCIMENTO, 1978, p. 69-70).

\begin{abstract}
A palavra senha dêsse $[s i c]$ imperialismo de brancura e do capitalismo que lheé inerente, responde a apelidos bastardos como assimilação, aculturação e miscigenação, mas sabemos que embaixo da superfície teórica permanece intocada a crença na inferioridade do Africano e seus descendentes. (NASCIMENTO, 1978, p. 93).
\end{abstract}

Essa visão de antirracismo institucional tem raízes profundas e foi perpetuada pelo mundo. Na última edição do Dictionary of Race and Ethnic Relations de Cashmore, o Brasil é definido como um país em que as diferenças classistas são extremamente demarcadas, e que o poder econômico muitas vezes prevalece sobre a raça. A classe e a cor as vezes se misturam, mas não se correspondem, até porque a raça é matéria de foro íntimo, não uma definição coletiva (CASHMORE, 1994).

O fim da segregação racial e o movimento dos direitos civis nos Estados Unidos contribuíram para que essas percepções começassem a mudar. Foi quando as desigualdades raciais foram atribuídas às desigualdades sociais, à educação escolar, à seletividade no mercado de trabalho, à pobreza, à organização familiar e, dessa forma, as denúncias das desigualdades raciais no Brasil, por muitos anos mascaradas, passaram a ser um item de discussão racial (GUIMARÃES, 2009, p. 43).

No Brasil, esse sistema de hierarquização social por classes, ocupação, renda, origem familiar, cor e educação formal foi fundado sobre a divisão que, por três séculos, sustentou a escravidão, dividindo os brasileiros entre elite/povo e brancos/negros, dicotomias que se reforçam simbólica e materialmente (GUIMARÃES, 2009, p. 49).

O racismo possui caráter sistêmico, não é apenas uma atitude discriminatória, é "um processo em que condições de subalternidade e de privilégios que se distribuem entregrupos raciais" gera efeitos na política, economia, na socialização. Ele divide os espaços em bairros, guetos, hospitais, serviços públicos, onde o acesso, em geral, se dá para um grupo 
(ALMEIDA, 2019, p. 23).

No ano de 2019, em pesquisa realizada pelo Instituto Brasileiro de Geografia e Estatística (IBGE) divulgada no informativo "Desigualdades sociais por cor ou raça no Brasil", constatou-se que há o triplo de negros entre os $10 \%$ da população com menores rendimentos per capita do que no grupo de $10 \%$ da população com maior renda. Entre os $10 \%$ com maior rendimento per capita, brancos eram 70,6\%, enquanto os pretos e pardos eram $27,7 \%$. Ressalte-se, ainda, que no ano de $2018,55,8 \%$ da população se declarou preta ou parda. Além disso, na classe de rendimento mais elevado, apenas 11,9\% das pessoas que ocupam cargos gerenciais eram pretas ou pardas, entre os brancos esse percentual é de 89,5\% (INSTITUTO BRASILEIRO DE GEOGRAFIA E ESTATÍSTICA, 2019).

É o resultado do funcionamento das instituições jurídicas, econômicas e políticas, geralmente controladas por certos grupos que, mesmo indiretamente, confere privilégios ou desvantagens com base na raça. Trata-se do racismo institucional (ALMEIDA, 2019,p. 25).

Essas instituições são vinculadas à ordem social. O racismo não é algo criado por elas, mas reproduzido (ALMEIDA, 2019, p. 32), são materializações dessa ordem, aqui está o racismo estrutural (ALMEIDA, 2019, p. 31). As instituições são racistas porque a sociedade é racista, gerando uma prática sistemática que gera efeitos na organização política, econômica e jurídica (ALMEIDA, 2019, p. 33).

O racismo gera desigualdade que, visto os dados estatísticos acima, divulgados pelo IBGE, atinge mais os negros do que os brancos no Brasil, o que afeta o acesso à educação, saúde, segurança pública e aumenta a violência. Assim, serão analisados, a seguir, os crimes violentos no Brasil.

\subsection{Armas de fogo e crimes violentos - dados estatísticos da violência contra os negros no Brasil}

O traço dessa desigualdade de cor ou raça, que aqui será analisado, é a concentração dos índices de violência letal na população negra. Apenas no ano de 2018, segundo o IBGE, os negros representaram $75,7 \%$ das vítimas de homicídios, como uma taxa de 37,8 por 100 mil habitantes; entre os não negros a taxa foi de 13,9. A cada indivíduo não negro morto em 2018, 2,7 negros foram mortos (INSTITUTO DE PESQUISA ECONÔMICA APLICADA; FÓRUM BRASILEIRO DE SEGURANÇA PÚBLICA, 2020, p. 47).

A Pesquisa Nacional por Amostra de Domicílios Contínua de 2016, realizada pelo 
IBGE, apontou um crescimento de 3,4\% da população brasileira, totalizando 205,5 milhões de brasileiros em 2016. Destes, 90,9 milhões se classificaram como brancos, 16,8 milhões como pretos, 95,9 milhões como pardos. Foi registrada uma redução na população de brancos (queda de 3,4\%), que passou a representar 47,7\% da população. Houve, também, um crescimento da população negra, que engloba os pretos $(+6,6 \%)$ e pardos $(+14,9 \%)$, passando agora a ser a maioria no país de $54,9 \%$, sendo $46,7 \%$ autodeclarados pardos e $8,2 \%$ autodeclarados pretos (SARAIVA, 2017).

Os negros figuram como pouco mais de $50 \%$ da população. No entanto, há o triplode negros entre a população mais pobre. Os negros representam apenas $27 \%$ da população com maior rendimento (INSTITUTO BRASILEIRO DE GEOGRAFIA E ESTATÍSTICA, 2020, p. 4-5). O combate às desigualdades sociais no Brasil é, também, uma forma de combate ao racismo que ocasiona, aos negros, maiores índices de vulnerabilidade econômica e social e, ainda, envolve aspectos históricos e culturais.

O Atlas da violência do ano de 2020 apresenta o padrão de vitimização por raça/cor, o que, mais uma vez, demonstrou a superioridade dos homicídios de homens e mulheres negros em relação a homens e mulheres não negros, sendo respectivamente de $74,0 \%$ e 64,4\%. Ao se comparar tais indicadores com a edição anterior, com dados de 2007 a 2017, verifica-se que também ocorreu um aumento anual, pois anteriormente o índice era de $73,3 \%$ para homens e $63,4 \%$ para mulheres. Importante salientar que em números totais, as mulheres negras representam $68 \%$ das vítimas do sexo feminino no país, com a taxa de 5,2 por 100 mil habitantes, praticamente o dobro das mulheres não negras (INSTITUTO DE PESQUISA ECONÔMICA APLICADA; FÓRUMBRASILEIRO DE SEGURANÇA PÚBLICA, 2020, p. 68).

A desigualdade racial, nos indicadores sociais da violência, fica mais evidente quando se constata que a redução de $12 \%$ na taxa de homicídios ocorridos entre os anos de 2017 e 2018 se concentrou mais entre a população não negra - foi 7,6\% menor. Entre2008 e 2018, as taxas de homicídio apresentaram um aumento de 11,5\% para os negros e uma diminuição de $12,9 \%$ para os não negros (INSTITUTO DE PESQUISA ECONÔMICA APLICADA; FÓRUM BRASILEIRO DE SEGURANÇA PÚBLICA, 2020, p. 47).

Dados fornecidos pelo Anuário de Segurança Pública de 2020 só reforçam a desigualdade racial. Em 15 anos, a proporção de negros nas prisões aumentou em 14\%, enquanto a de não negros foi reduzida em 19\%. No ano de 2019, os negros representaram $66,7 \%$ da população carcerária, enquanto a população não negra representou 33,3\%. A cada 
não negro preso no Brasil, dois negros foram presos (INSTITUTO DE PESQUISA ECONÔMICA APLICADA; FÓRUM BRASILEIRO DE SEGURANÇA PÚBLICA, 2020, p. 307).

A polícia brasileira, civil e militar, também foi alvo da pesquisa realizada pelo Anuário de Segurança Pública, que constatou que em pesquisa realizada pelo Perfil dos Profissionais de Segurança Pública da Secretaria Nacional de Segurança Pública (SENASP), em 2015, 53\% dos policiais brasileiros eram brancos e 34,9\% negros. No entanto, há a prevalência de policiais negros entre as vítimas de violência letal, correspondendo a $69,1 \%$ dos policiais INSTITUTO DE PESQUISA ECONÔMICA APLICADA; FÓRUM BRASILEIRO DE SEGURANÇA PÚBLICA, 2020, p. 76-80).

Há uma crescente para o número de vítimas causadas pela intervenção policial no Brasil. Em 2019, o país atingiu o maior número de mortes em decorrência de intervenções policiais desde 2013, quando o indicador passou a ser monitorado pelo Fórum Brasileirode Segurança Pública. No primeiro semestre de 2020, durante a pandemia do COVID-19, que diminuiu a circulação de pessoas, as mortes por intervenção policial cresceram $6 \%$ em números absolutos, fazendo 3181 vítimas (INSTITUTO DE PESQUISA ECONÔMICA APLICADA; FÓRUM BRASILEIRO DE SEGURANÇA PÚBLICA, 2020, p. 86)

Analisando o perfil das vítimas por intervenção policial, constatou-se que 99,2\% dos mortos eram homens e apenas $0,8 \%$ mulheres. No tocante a cor/raça, $79,1 \%$ das vítimas eram negras, percentual superior à média nacional, que é de 74,4\% (INSTITUTODE PESQUISA ECONÔMICA APLICADA; FÓRUM BRASILEIRO DE SEGURANÇA PÚBLICA, 2020, p. 89-90).

Resta demonstrado, estatisticamente, que a vulnerabilidade dos negros à violênciano Brasil é uma realidade completamente distinta dos não negros. Os negros figuram como as maiores vítimas entre os jovens, entre as mulheres, entre os policiais mortos de forma violenta, entre as vítimas de intervenções policiais, sendo que esses são pouco maisde $50 \%$ da população e, em alguns casos, chegam a ser o triplo de vítimas, o que demonstra a desigualdade racial e o racismo existentes no país.

Não se pode deixar que a polarização fomente esse racismo, o caminho democrático é a tolerância que torna a paz possível e que substitui a cultura da guerra pelada paz. A tolerância é, acima de tudo, uma atitude de reconhecer os direitos humanos universais, respeitar a liberdade fundamental do outro, a tutela internacional que busca 
afastar a intolerância, o preconceito, a discriminação daqueles que não fazem parte das etnias, opiniões, orientação sexual, cor, religião das maiorias (SÉGUIN, 2002, p. 54-55).

Dessa forma, cabe ao Estado promover ações e o ordenamento jurídico a regulamentação de leis que visem evitar ou disseminar a intolerância e a discriminação.

A polarização política, a intolerância e o racismo interfiriram no ordenamento jurídico brasileiro, medidas travestidas de democráticas, que possuem reflexos diretos na vulneração das minorias, são antidemocráticas, pois não observam os princípios da liberdade e igualdade, não protegem os direitos dos grupos vulneráveis, no caso em tela, os negros. Não se deve minimizar as agressões praticadas pela maioria contra as minorias, mesmo que travestidas de liberdade individual ou autonomia privada.

\section{CONCLUSÃO}

No Brasil, o racismo é perpetuado de forma sistêmica e institucional, numconstante processo de concessão de privilégios, distribuídos de acordo com o grupo racialou retirada de direitos. Os dados estatísticos da violência contra negros no país demonstram essa realidade, além de serem um forte indicativo da desigualdade social criada pela cor ou raça. Enquanto a mortalidade de não negros diminui, os negros figuramcomo as maiores vítimas. Em alguns casos, chegam a ser o triplo de vítimas, sendo que representam pouco mais de $50 \%$ da população (INSTITUTO DE PESQUISA ECONÔMICA APLICADA; FÓRUM BRASILEIRO DE SEGURANÇA PÚBLICA, 2020).

No ano de 2018, o grupo de conservadores venceu a disputa eleitoral e elegeu o presidente Jair Messias Bolsonaro, cuja campanha foi marcada pela forte defesa da flexibilização do porte, da posse e do comércio de armas e munições em nome da liberdade, da autonomia privada e da segurança pública.

No entanto, deixou-se de se observar que a flexibilização gera um contexto excludente, já que os negros figuram como as maiores vítimas da violência no país. A flexibilização do comércio, porte e posse de armas e munições tornou-se medida extremista e, o extremismo, seja de "esquerda" ou de direita", é antidemocrático; o moderantismo é caminho da democracia.

A divisão causada pela polarização coloca a "esquerda" contra a "direita". No entanto, o que deveria ocorrer é a sucessão pacífica e democrática, sempre atenta aos 
critérios de liberdade e igualdade. Ressalta-se que o critério da liberdade para uma demarcação democrática não se resume à livre escolha de um grupo ou da maioria

A Constituição da República Federativa do Brasil (BRASIL, 2021) é igualitarista, possui o fim de diminuir as desigualdades sociais, pois acredita que essas são causadas pela sociedade e, em nome da igualdade natural, condena a desigualdade social.

Até mesmo a busca pela igualdade gera limitações à liberdade, como em alguns casos, quando o Estado intervém com medidas igualitárias nas escolhas da esfera privada. Assim, deveria o governo agir constitucionalmente, perseguindo a liberdade democrática,que é a busca pela proteção da dignidade da pessoa humana e implementar medidas igualitárias, as quais diminuam ou findam a vulneração dos negros no país.

Deve-se buscar, no Estado Democrático de Direito, o fim da vulnerabilidade das minorias, pois esta vulneração advém do poder dos grupos majoritários, o que vai no caminho contrário dos princípios democráticos. Não se pode deixar que grupos dominantes utilizem da violência como um meio de solução de conflitos, seja deturpandoo conceito de liberdade ou na busca de interesses privados.

A vulneração de grupos representa o oposto da busca pela liberdade e igualdade, pois gera a falta de poder, subjugação, violência e marginalização. No Brasil, ainda podeser observado o racismo de Estado, que se perpetua por meio de preconceitos, discriminação, intolerâncias infundadas, que somente servem como justificativa para a violência, para intervenções estatais abruptas.

É uma forma de manutenção do poder, que retira do governo a responsabilidade pelas desigualdades sociais, pela subjugação racial, já que não se trata mais de desigualdade social e sim biológica. Tal ideia é reforçada estatisticamente, já que a maioria atuante no poder político, econômico ou jurídico não é formada pela população negra; assim, se eximem de promover políticas públicas que buscam o ideal igualitarista constitucional.

O racismo estatal, as minorias vulneráveis, somadas à polarização de grupos, criam um sistema em que o debate político é contaminado e, em alguns casos, resultam na legalização de políticas antidemocráticas que causam mais vulnerabilidade e submissão, ferindo o ordenamento jurídico brasileiro.

Em sociedades democráticas, as intervenções estatais se dão, geralmente, por intermédio de leis editadas por representantes eleitos. No entanto, deve-se sempre garantiras liberdades individuais e a dignidade da pessoa humana, pois, caso estas não estejam 
asseguradas, a democracia não passa de uma mera representação.

Assim, confirma-se a hipótese da pesquisa, ou seja, a de que a crescente polarização de grupos fomenta a intolerância e o racismo, ultrapassando a esfera do debate político ou civil, contaminando o ordenamento jurídico. Assim, incrementando a vulneração de grupos minoritários, em especial, os negros, malferindo o princípio da dignidade da pessoa humana.

Dessa forma, os direitos humanos e a soberania do povo são os garantidores do Estado Democrático de Direito. O Direito só é legitimo quando não vai de encontro comos ideais de justiça, da solidariedade universal e os princípios de uma autonomia privadaética.

\section{REFERÊNCIAS}

ALMEIDA, Silvio Luiz de. Racismo estrutural. São Paulo: Sueli Carneiro; Pólen,2019.

APPIAH, Kwame Anthony. Racisms. In: GOLDBERG, David Theo. Anatomy of racism. Minneapolis: University of Minnesota Press, 1990. p. 3-17.

ARENDT, Hannah. Origens do totalitarismo. Tradução de Roberto Raposo. São Paulo: Companhia das Letras, 1997.

BERNARDES, Bruno Paiva. Conjecturas sobre a aplicação do minimalismo judicialao ordenamento jurídico brasileiro e sua democraticidade jurídica. 2019.

Dissertação (Mestrado em Direito) - Programa de Pós-Graduação Stricto Sensu em Direito, Universidade FUMEC, Belo Horizonte, 2019. Disponível em:

https://repositorio.fumec.br/xmlui/handle/123456789/590. Acesso em: 28 mar. 2021.

BRASIL. [Constituição (1988)]. Constituição da República Federativa do Brasil de 1988. Brasília, DF: Presidência da República, [2021a]. Disponível em:

http://www.planalto.gov.br/ccivil_03/Constituicao/Constituicao.htm. Acesso em: 28 mar. 2021.

CARMO, Cláudio Márcio do. Grupos minoritários, grupos vulneráveis e o problema da (in)tolerância: uma relação linguístico-discursiva e ideológica entre o desrespeito e a manifestação do ódio no contexto brasileiro. Revista do Instituto de Estudos

Brasileiros, [s. l.], n. 64, p. 201-203, ago. 2016. Disponível em:

https://doi.org/10.11606/issn.2316-901X.v0i64p201-223. Acesso em: 28 mar. 2021.

CARVALHEIRO, José Ricardo. Da representação mediática à recepção política:

discursos de uma minoria. Sociologia, Problemas e Práticas, [s. l.], n. 51, p. 73-93, 2006.

FÓRUM BRASILEIRO DE SEGURANÇA PÚBLICA. Anuário Brasileiro de Segurança Pública. [S. l.]: Fórum Brasileiro de Segurança Pública, 2020. Disponível 
em: https://forumseguranca.org.br/wp-content/uploads/2020/10/anuario-14-2020-v1interativo.pdf. Acesso em: 28 mar. 2021.

GONTIJO, Lucas de Alvarenga; BICALHO, Mariana Ferreira. Psicologia das massas e racismo de Estado: o ultraconservadorismo contemporâneo. Delictae Revista de Estudos Interdisciplinares sobre o Delito, [s. l.], v. 4, n. 7, p. 236-270, dez. 2019.

Disponível em: http://www.delictae.com.br/index.php/revista/article/view/109. Acessoem: 28 mar. 2021.

GUIMARÃES, Antônio Sérgio Alfredo. Racismo e antirracismo no Brasil. 3. ed. São Paulo: Editora 34, 2009.

GUSTIN, Miracy Barbosa de Sousa; DIAS, Maria Tereza Fonseca; NICÁCIO, Camila Silva. (Re)pensando a pesquisa jurídica: teoria e prática. 5. ed. rev., ampl. e atual. São Paulo: Almedina, 2020.

HOFSTADTER, Richard. The paranoid style in American politics and other essays. Cambridge: Harvard University Press, 1996

INSTITUTO BRASILEIRO DE GEOGRAFIA E ESTATÍSTICA. Estudos e pesquisas: informação demográfica e socioeconômica $n^{\circ} 41$. Rio de Janeiro: IBGE, [2020]. Disponível em:

https://biblioteca.ibge.gov.br/visualizacao/livros/liv101681_informativo.pdf. Acessoem: 28 mar. 2021.

INSTITUTO BRASILEIRO DE GEOGRAFIA E ESTATÍSTICA. Pesquisa das características étnico-raciais da população - PCERP. Rio de Janeiro: IBGE, [2008]. Disponível em: https://www.ibge.gov.br/estatisticas/sociais/populacao/9372caracteristicas-etnico-raciais-da-populacao.html $?=\& \mathrm{t}=$ resultados. Acesso em: 28 mar. 2021.

INSTITUTO BRASILEIRO DE GEOGRAFIA E ESTATÍSTICA. Sinopse do Censo Demográfico. Rio de Janeiro: IBGE, 2011. Disponível em: https://biblioteca.ibge.gov.br/index.php/biblioteca-catalogo?view=detalhes\&id=249230. Acesso em: 28 mar. 2021.

INSTITUTO DE PESQUISA ECONÔMICA APLICADA; FÓRUM BRASILEIRO DE SEGURANÇA PÚBLICA. Atlas da violência: taxa de homicídios por armas de fogo. Brasília, DF: IPEA, 2020. Disponível em: https://www.ipea.gov.br/atlasviolencia/dadosseries/35. Acesso em: 28 mar. 2021.

INSTITUTO DE PESQUISA ECONÔMICA APLICADA; FÓRUM BRASILEIRO DE SEGURANÇA PÚBLICA. Atlas da violência: taxa de homicídios. Brasília, DF: IPEA, 2020. Disponível em: https://www.ipea.gov.br/atlasviolencia/dados-series/20. Acesso em: 28 mar. 2021.

INSTITUTO DE PESQUISA ECONÔMICA APLICADA; FÓRUM BRASILEIRO DE SEGURANÇA PÚBLICA. Atlas da violência. Brasília: São Paulo: Rio de Janeiro: IPEA, 2019. Disponível em: https://www.ipea.gov.br/atlasviolencia/download/19/atlas-daviolencia-2019. Acesso em: 28 mar. 2021. 
LEVITSKY, Steven; ZIBLATT, Daniel. Como as democracias morrem. Rio de Janeiro: Editora Zahar, 2018.

NASCIMENTO, Abdias do. O genocídio do negro brasileiro: processo de um racismo mascarado. Rio de Janeiro: Paz e Terra, 1978.

ORTELLADO, Pablo; RIBEIRO, Márcio Moretto. Gráficos mostram polarização política nas redes sociais no Brasil. Galileu, [s. l.], 10. ago. 2018. Disponível em: https://revistagalileu.globo.com/Sociedade/noticia/2018/08/graficos-mostrampolarizacao-politica-nas-redes-sociais-no-brasil.html. Acesso em: 28 mar. 2021.

OUTSIDER [verbete]. In: INSTITUTO ANTÔNIO HOUAISS. Grande Dicionário Houaiss. [S. l.: s. n.], [2021]. Disponível em: https://houaiss.uol.com.br/. Acesso em: 28 mar. 2021.

RIFIOTIS, Theophilos. Nos campos da violência: diferença e positividade. [S. l.]: Laboratório de Estudos das Violências, [2006]. Disponível em: https://www.academia.edu/3059021/Nos_campos_da_viol\%C3\%AAncia_diferen\%C3 \%A7a_e_positividade. Acesso em: 28 mar. 2021.

ROGERS, Wendy; BALLANTYNE, Angela. Populações especiais: vulnerabilidade e proteção. Revista Eletrônica de Comunicação, Informação \& Inovação em Saúde, Rio de Janeiro, v. 2, p. 31- 41, dez. 2008.

SARAIVA, Adriana. População chega a 205,5 milhões, com menos brancos e mais pardos e pretos. Agência IBGE Notícias, [s. l.], 24 nov. 2017. Disponível em: https://agenciadenoticias.ibge.gov.br/agencia-noticias/2012-agencia-denoticias/noticias/18282-populacao-chega-a-205-5-milhoes-com-menos-brancos-e-maispardos-e-pretos. Acesso em: 28 mar. 2021.

SÉGUIN, Elida. Minorias e grupos vulneráveis: uma abordagem jurídica. Rio de Janeiro: Forense, 2002.

SUNSTEIN, Cass R. A era do radicalismo: entenda por que as pessoas se tornam extremistas. Trad. Lucienne Scalzo. Rio de Janeiro: Elsevier, 2010.

WELTER, Izabel Preis; CASTRO, Matheus Felipe de. O direito à autonomia privada no Estado de Bem Estar Social: o paradoxo de uma inversão. In: ENCONTRO NACIONAL DO CONPEDI, 23., 2014, Florianópolis. Anais [...]. Florianópolis: CONPEDI, 2014. p. 421-438. Disponível em:

http://www.publicadireito.com.br/artigos/?cod=db508d3639b6835d. Acesso em: 28 mar. 2021 